\title{
Análisis de algunas barreras del ambiente construido para la actividad fisica en la Ciudad de Cuernavaca, Morelos, México
}

\author{
Analysis of some environmental barriers for physical \\ activity Cuernavaca City, Morelos, México
}

Jesús David Cortés Gil ${ }^{1}$, Emanuel Orozco Núñez ${ }^{1}$, Giovanna Laura María Gatica Domínguez ${ }^{1}$, Enrique Cifuentes²

Forma de citar: Cortés Gil JD, Orozco Nuñez E, Gatica Dominguez GLM, Cifuentes E. Análisis de algunas barreras del ambiente construido para la actividad física en la Ciudad de Cuernavaca, Morelos, México. Rev Univ Ind Santander Salud. 2016; 48(2): 196-205. DOI: http://dx.doi.org/10.18273/revsal.v48n2-2016004 (c) (1) అ

\section{RESUMEN}

Introducción: La actividad física (AF) es un factor de protección ante múltiples enfermedades. Las recomendaciones mundiales para la AF están bien establecidas y son difundidas en todos los escenarios posibles, pero el ambiente construido podría presentar múltiples barreras para seguir dichas recomendaciones. Objetivo: Analizar algunas barreras del ambiente construido para la actividad física por niveles de marginación en la ciudad de Cuernavaca, México. Materiales y métodos: Empleando el programa Atlas ti 5.0, se categorizaron los datos obtenidos de 170 guías de observación. Se realizó el análisis de un acervo fotográfico de 341 imágenes de 20 AGEBS de la ciudad de Cuernavaca, utilizando un análisis de imágenes fijas connotativo, denotativo y por 3 categorías (Calzadas, tránsito y espacios deportivos). Se utilizó el programa Stata 12.0 para obtener frecuencias y porcentajes. Resultados: Se identificaron deficiencias en el diseño y uso de espacios como las banquetas, falta de señalización e inseguridad de las vías públicas. Se encontró carencia de espacios para la práctica de la actividad física. Solo hay una presencia del 10\% de espacios deportivos en los 20 AGEBS estudiados. Se encontró que el $82.86 \%$ de las calles está en deficiente estado. La deficiente iluminación vial, carencia de ciclovías y grafitis con porcentajes importantes también se identificaron como barreras para la AF. Discusión: En Cuernavaca las posibilidades de acceso a espacios seguros, presentan múltiples barreras y por ende esta tendencia afecta de forma negativa la salud de los habitantes de la ciudad, además que no es congruente con las recomendaciones mundiales para la actividad física. Conclusiones: La identificación y abolición de las barreras deben estar dentro las prioridades de las políticas de salud públicas y las intervenciones deben procurar dicha transformación, de esta forma se superará la tendencia de solamente informar sobre los beneficios de la actividad física que predominan en la gran mayoría de las recomendaciones e intervenciones.

Palabras clave: Medio ambiente controlado, obesidad, actividad física, fotografías, inequidad social

1. Instituto Nacional de Salud Pública de México. Cuernavaca, México.

2. Harvard School of Public Health, Boston, United States of America.

Correspondencia: Jesús David Cortés Gil. Dirección: Instituto Nacional de Salud Pública de México, Cuernavaca Morelos - Calle antiguo camino a Tepoztlán 228- Dep 301 b- México. Correo electrónico: jdcorgil@gmail.com. Teléfono: +52 7773757920 


\section{ABSTRACT}

Introduction: Physical activity (PA) is a factor of protection against multiple diseases. Global recommendations for PA are well established and are spread in all possible scenarios, but the built environment could present multiple barriers to follow these recommendations. Objective: To Analyze some built environment barriers for physical activity by levels of marginalization in the city of Cuernavaca, Mexico. Material and methods: Using the software Atlas ti 5.0, data from 170 observation guides and were categorized. The analysis of a photographic collection of 341 images of 20 AGEBS of Cuernavaca was performed using an analysis connotative and denotative by 3 categories (roadways, traffic and sports areas). Stata 12.0 software was used to obtain frequencies and percentages. Results: Deficiencies in the design and use of spaces such as sidewalks, lack of signage and insecurity of public roads were identified. Lack of spaces for the practice of physical activity was found. There is only one presence of $10 \%$ of sports facilities in the 20 AGEBS studied. It was found that $82.86 \%$ of the streets are in poor condition. Poor street lighting, lack of bicycle paths and graffiti with significant percentages were also identified as barriers to PA. Discussion: In Cuernavaca the possibilities of access to safe spaces for FA have multiple barriers, this negatively affects the health of the habitants of the city, and that is not consistent with global recommendations for physical activity. Conclusions: Identifying and abolishing barriers must be within the priorities of public health policies and interventions should seek this transformation, to improve the tendency to only report on benefits of physical activity prevailing in the vast majority of programs.

Keywords: Environment controlled, social Inequity, obesity, physical activity, photographs

\section{INTRODUCCIÓN}

"Nadie sabe cómo aquel que se ejercita, lo que es el agua, el aire y el sol; los movimientos son una forma de honrar los días, de dar sentido a la vida"1.

La Organización mundial de la Salud nos dice que la importancia de la actividad física para la salud pública, la promoción de esta misma, la prevención de las enfermedades no transmisibles y la existencia de un número limitado de directrices nacionales sobre la actividad física para la salud en los países de ingresos bajos y medios como lo es México, resaltan la necesidad de desarrollar recomendaciones de alcance local y que puedan ser replicables en distintos escenarios, que aborden los aspectos como la frecuencia, la duración, la intensidad, el tipo y la cantidad total de actividad física necesaria para prevenir las enfermedades no transmisibles ${ }^{2}$.

El ambiente construido en el que vivimos presenta barreras que favorecen la inactividad física; la cual está íntimamente relacionada con la obesidad que es uno de los principales problemas de salud pública en México y en otros países del mundo. La obesidad consiste en una excesiva acumulación de grasa corporal en el organismo ${ }^{3}$. En México, de acuerdo con los resultados de la última Encuesta Nacional de Salud y Nutrición 2012, se reveló una prevalencia combinada de sobrepeso y obesidad en adultos de $73 \%$ para las mujeres y $69.4 \%$ para los hombres ${ }^{4}$.

El análisis socioeconómico de las barreras para la actividad física, puede favorecer la creación y ejecución de políticas, las cuales tienen enorme posibilidad de incrementar la actividad física. Algunos ejemplos de esas políticas consisten en velar por la accesibilidad y seguridad de la movilidad a pie, en bicicleta y con otras formas de transporte activo, o la existencia en las escuelas de instalaciones y espacios seguros para que los alumnos puedan realizar actividades físicas durante su tiempo libre ${ }^{5}$. Marmot afirma, que un elemento central de las recomendaciones de la Comisión de Determinantes Sociales de la OMS es que se creen las condiciones para que la población se emancipe y tenga libertad para vivir una vida próspera. Es importante mencionar que el enfoque de los determinantes sociales, plantea considerar todas aquellas condiciones socioeconómicas y culturales que hacen que mueran y enfermen con mayor frecuencia las personas menos favorecidas, que aquellas que están en condiciones más favorables; para sortear con éxito las contingencias que los afectan y que hacen que las inequidades sean cada vez mayores ${ }^{6}$, como es el caso de Cuernavaca.

En el presente estudio la dimensión donde interactúan las variables es el ambiente construido; el cual se define como el área urbana que nos rodea, desde caminos y parques en las ciudades, hasta las casas y apartamentos donde las personas viven; incluye todos estos espacios $^{7}$. Los estudios como este son fundamentales porque pueden generar evidencia para promover un ambiente físico saludable protegiendo la salud e impedir enfermedades ${ }^{8}$. Son variados los beneficios de la actividad física, como un efecto moderado en la reducción de la ansiedad, mejora las auto-percepciones físicas, en algunos casos la autoestima, los estados de ánimo y mejorar algunas funciones cognitivas ${ }^{9}$. 
Análisis de algunas barreras del ambiente construido para la actividad física en la Ciudad de Cuernavaca, Morelos, México

Para la ciudad de Cuernavaca es importante identificar las barreras que tiene para que sus habitantes y visitantes se desplacen y realicen actividad física ya que posee muy pocos espacios para realizarla, una saturación de vehículos de servicio público, un diseño de calzadas deficiente y casi nulo en varias áreas y una geografía poco estimulante para ejercitarse porque la ciudad está construida en una superficie inclinada.

Durante el último congreso de salud pública y actividad física realizado en Sídney Australia (2012) uno de los temas centrales fue en el área de medidas e instrumentos para la evaluación de los entornos y la actividad física ${ }^{10}$. En este sentido la presente investigación también pretende ser un instrumento y plantear una metodología para dicha evaluación del entorno, a través del análisis de las barreras del ambiente construido para la actividad física por AGEBS (Área urbana compuesta por calles y manzanas que representa una unidad Geoestadística Básica) ${ }^{11}$ sin perder el propósito principal de probar como el ambiente construido en áreas socioeconómicamente variadas de Cuernavaca tiene barreras relevantes para la actividad física y que la situación observada refleja lo que ocurre en ciudades o poblaciones similares.

\section{MATERIAL Y MÉTODOS}

Este es un estudio Cuali-Cuantitativo, Transversal descriptivo; que consiste en un análisis secundario de una base de datos producto de un estudio ecológico titulado "Determinantes ambientales de la obesidad infantil y políticas públicas en México", realizado en la ciudad de Cuernavaca durante los años 2010 y 2012. Se seleccionaron aleatoriamente 20 AGEBS de distintos niveles de marginación (tres niveles: bajo, medio y alto) con altas prevalencias de sobrepeso y obesidad según los datos de ENSANUT 20064, los cuales se incorporaron al Sistema de Información Geográfica (SIG). (Figura 1)

Para la recolección de datos se utilizaron 170 guías de observación y registros fotográficos de 341 imágenes fijas e inventarios de establecimientos deportivos, con el objeto de documentar datos sobre el ambiente construido. Para la selección de AGEBS, se utilizó el programa ArcGIS 9.3. Para integrar un Sistema de Información Geográfica de la Zona Metropolitana de Cuernavaca, se incorporó información del Marco Geoestadístico Municipal 2005 de INEGI, la cartografía urbana censal 2005 y la información demográfica resultante del II Conteo de Población y Vivienda 2005. (Figura 1)

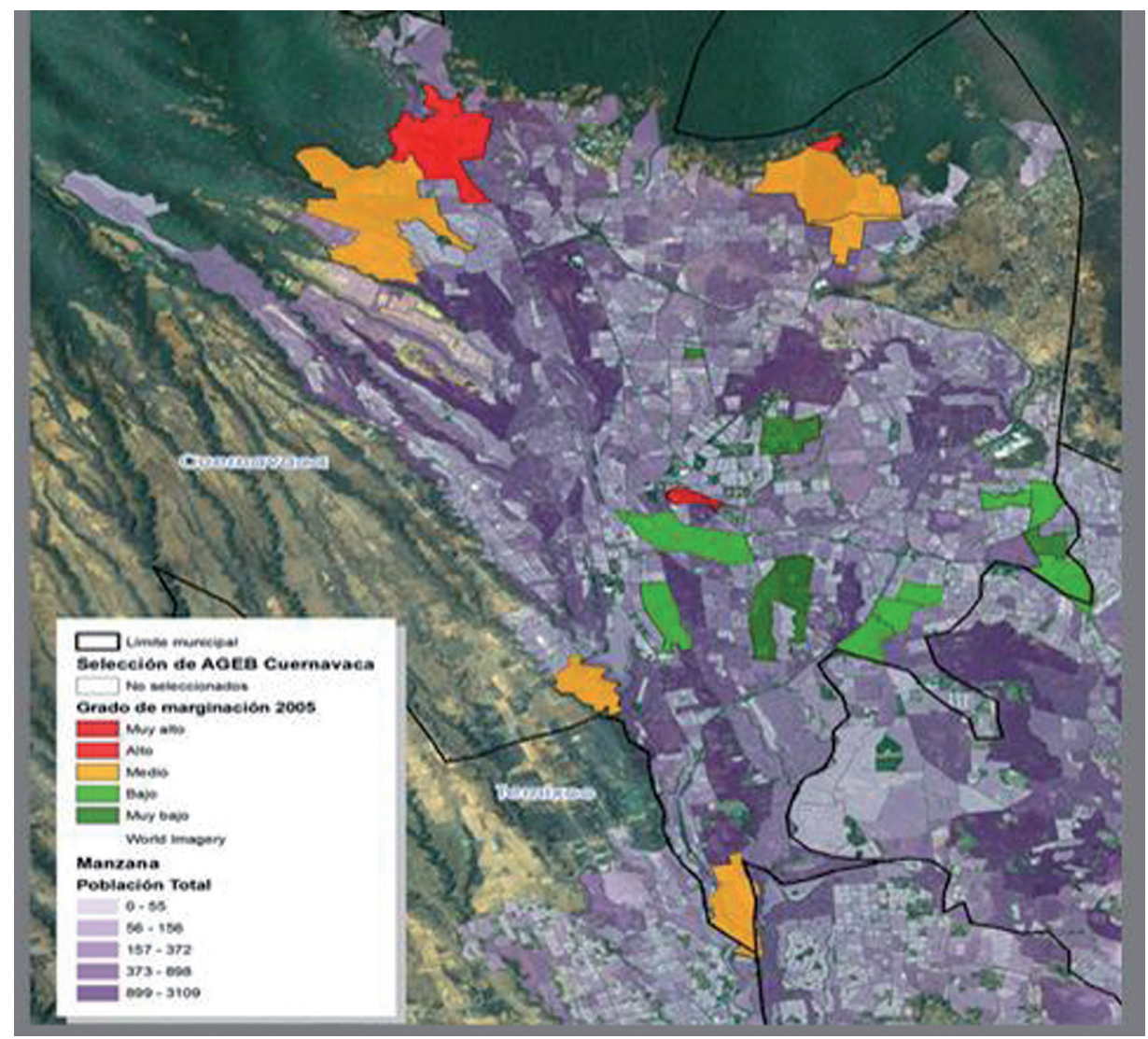

Figura 1. AGEBS seleccionados con nivel de marginación correspondiente INEGI 2010. 


\section{Levantamiento de datos por guías de observación}

Se elaboró un mapa de referencia para el levantamiento de la encuesta observacional a través de 170 guías de observación. En un mapa impreso se ubicaron y codificaron mediante un folio único cada una las áreas aleatoriamente elegidas para observar, las observaciones incluyeron evidencias fotográficas, las cuales también fueron codificadas de manera que fueron relacionadas e incorporadas a la base de datos y posteriormente integradas al SIG. Dichas fotografías correspondieron al mismo ángulo de observación del observador dirigidas al área indicada para observar. A continuación se ilustra las variables que fueron tenidas en cuenta para las observaciones en cada calle (Tabla 1):

Tabla 1. Variables utilizadas en las guías de observación

\begin{tabular}{|c|c|}
\hline VARIABLE & DIGITO ASIGNADO \\
\hline TIPO DE COMUNIDAD & Urbana 1 - Semi-urbana 2 - Rural 3 \\
\hline TIPO DE VIVIENDA & Casas unifamiliares 1 - Zona industrial 2 - Zona comercial 3- Fraccionamiento 4 - Institución 5 \\
\hline NIVEL SOCIOECONÓMICO & Bajo 1- Bajo/Medio 2 - Medio 3 - Medio/Alto 4- Alto 5 \\
\hline $\begin{array}{l}\text { QUE O QUIENES CIRCULAN } \\
\text { POR LAS CALLES }\end{array}$ & Vehículos particulares 1- Personas 2 - Vehículos de servicio público 3- Motocicletas 4 \\
\hline BANQUETAS & Amplias 1- Angostas 2- Obstruidas o bloqueadas 3- No hay 4 - Solo a un lado de la calle 5 - Solo en tramos 6 \\
\hline ALUMBRADO PÚBLICO & Si hay 1- No hay 2 - Si hay en mal estado 3 - Escasas 4 \\
\hline PUENTES PEATONALES & Si hay 1 - No hay 2 \\
\hline CICLOVIAS & Si hay 1 - no hay 2 \\
\hline VIAS DE TRANSPORTE & En buen estado 1 - Deterioradas (riesgos, mala señalización, estrechas, inseguras) 2 \\
\hline $\begin{array}{l}\text { MODO DE TRANSPORTE } \\
\text { PREDOMINANTE }\end{array}$ & $\begin{array}{l}\text { Vehículos particulares } 1 \text { - Vehículos part y personas caminando } 2 \text { - Personas caminando } 3 \text { - Transporte } \\
\text { público } 4 \text { - Transporte público y veh. Particulares } 5 \text { - No se observó predominancia } 6 \text { - Bicicletas } 7\end{array}$ \\
\hline $\begin{array}{l}\text { SERVICIOS DE LA } \\
\text { COMUNIDAD }\end{array}$ & $\begin{array}{l}\text { No hay } 1 \text { - Escuelas públicas } 2 \text { - Escuelas privadas } 3 \text { - Áreas verdes } 4 \text { - Áreas comerciales } 5 \text { - Áreas deportivas } \\
6 \text {-Lugares religiosos } 7 \text { - Entidades gubernamentales } 8\end{array}$ \\
\hline CULTURA URBANA & Si hay 1- No hay 2 - Imágenes religiosas 3 - Publicidad de servicios 4 - Adornos 5 \\
\hline
\end{tabular}

Referente al aspecto cualitativo, los datos de las guías de observación que previamente habían sido organizados con el uso del programa Atlas ti 5.1, fueron descritos y resumidas por nivel de marginación. Respecto al aspecto cuantitativo a estos mismos datos de las guías de observación les fueron asignadas dígitos y se categorizaron las respuestas numéricamente una hoja de cálculo en el programa Microsoft Excel para posteriormente ser analizadas por el programa Stata 12.0 (StataCorp, College Station, TX, USA), obteniendo frecuencias y porcentajes. Se realizó el cruce de algunas variables que se expresaron en gráficas de las distintas categorías.

\section{Análisis de imágenes}

El análisis del acervo fotográfico se realizó por cada una de las 341 imágenes fijas, cada fotografía fue tomada desde el punto de inicio de cada calle teniendo el observador un rango hacia el frente de toda la extensión de la misma de aproximadamente entre 40 y 90 metros. La categorización por imagen fué de la siguiente manera:

1. Caracterización denotativa (Resumen de cada imagen): descripción de objetos, personas, decorado o paisajes, tiene valores formales que son elementos visuales, conceptuales, relación y procedimentales ${ }^{12}$.

2. Caracterización connotativa: Valoración de los elementos presentes en la imagen ${ }^{12}$.

3. Descriptor: Concepto final de la relación entre los objetos de la imagen como barreras o facilitadores para la actividad física.

Posteriormente se realizó una síntesis de descriptores por grado de marginación y AGEBS en 3 categorías:

A. Calzadas: estado de banquetas, valoración referente a barreras para la actividad física.

B. Espacios deportivos: Valoración de las áreas destinadas a la actividad física y al deporte.

C. Tránsito: Transporte urbano, valoración sobre su impacto como barrera para la actividad física.

Como se muestra en el ejemplo a continuación a cada fotografía le fue asignada una letra por la ubicación en la que fue tomada, un código, número y nombre de la calle en la que fue tomada. 
Análisis de algunas barreras del ambiente construido para la actividad física en la Ciudad de Cuernavaca, Morelos, México

Tabla 2. Ejemplo de esquema de clasificación de las imágenes

\begin{tabular}{cccccccc}
\hline $\begin{array}{c}\text { No. } \\
\text { fotografía }\end{array}$ & Código & Calle & $\begin{array}{c}\text { Categoría } \\
\text { C: Calzadas } \\
\text { T: Tránsito } \\
\text { E: Espacios }\end{array}$ & $\begin{array}{c}\text { A: calle izquierdo } \\
\text { del observador } \\
\text { B: lado contrario } \\
\text { C: central }\end{array}$ & $\begin{array}{c}\text { Caracterización } \\
\text { denotativa }\end{array}$ & $\begin{array}{c}\text { Caracterización } \\
\text { connotativa }\end{array}$ & Descriptor \\
\hline 1 & P1020741 & Laurel & C & A & $\begin{array}{l}\text { Calle, carros, } \\
\text { banqueta, árbol, } \\
\text { basura, viviendas. }\end{array}$ & $\begin{array}{l}\text { Banqueta obstruida y } \\
\text { destruida por árbol. } \\
\text { Calzada en mal estado. riesgo para peatones }\end{array}$ \\
$\begin{array}{c}\text { Calal } \\
\text { desfavorable y de alto }\end{array}$ \\
\hline
\end{tabular}

\section{RESULTADOS}

El modelo socio-ecológico reconoce el efecto potencial que los ambientes urbanos construidos y las políticas públicas tienen sobre los diferentes dominios de una vida $\operatorname{activa}^{13}$. En esta línea los resultados son presentados a lo largo de varios temas como son: ambiente construido, banquetas, ciclovías, espacios deportivos e índices de marginación alto, medio y bajo.

\section{Ambiente construido}

En los AGEBS de nivel de marginación alto y medio se reportó dos espacios deportivos públicos, carencia total de puentes peatonales, pocos grafitis, ausencia total de ciclovías, escasa presencia de banquetas, y la mayoría de las existentes están obstruidas. La iluminación no tiene cobertura total ni para las viviendas ni en el alumbrado público. Predomina la presencia de banquetas aunque en mal estado, gran circulación vehicular y a que no hay condiciones seguras para caminar, poca señalización vial, muy poca presencia de espacios deportivos. Se encontraron como barreras para la actividad física: un solo espacio deportivo privado, carencia total de puentes peatonales, pocos grafitis, una ciclovía, presencia de banquetas, vías peatonales y vehiculares con poca señalización, buena iluminación.

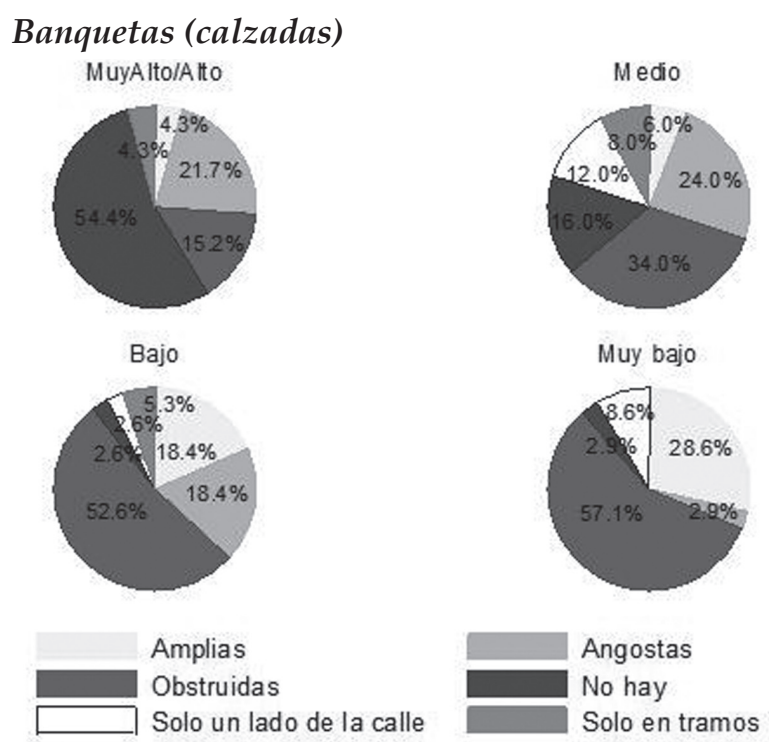

Figura 2. Estado de las banquetas por nivel de marginación
En la Figura 2, se puede apreciar de manera importante que existe un $54.35 \%$ de inexistencia de banquetas, solo un $4.34 \%$ de presencia de estas en buen estado, lo que representa una barrera para los peatones y es sinónimo de inseguridad vial, ya que si no hay banquetas las personas se ven obligadas a movilizarse por las vías de los automóviles. (Figura 1).

Se encontró un $57.14 \%$ de banquetas obstruidas y banquetas amplias un $28.57 \%$. La obstrucción de banquetas es una constante del ambiente construido. (Figura 1).

\section{Ciclovías}

La presencia de ciclovías en una ciudad representa una oportunidad para realizar actividad física de manera segura y generar un ambiente construido favorable para la protección de la salud. La Figura 3 , ilustra que en los 20 AGEBS estudiados solo hay una ciclovía, la cual tiene una distancia de 350 metros aproximadamente y representa el $1.18 \%$ del total de las ciclovías.

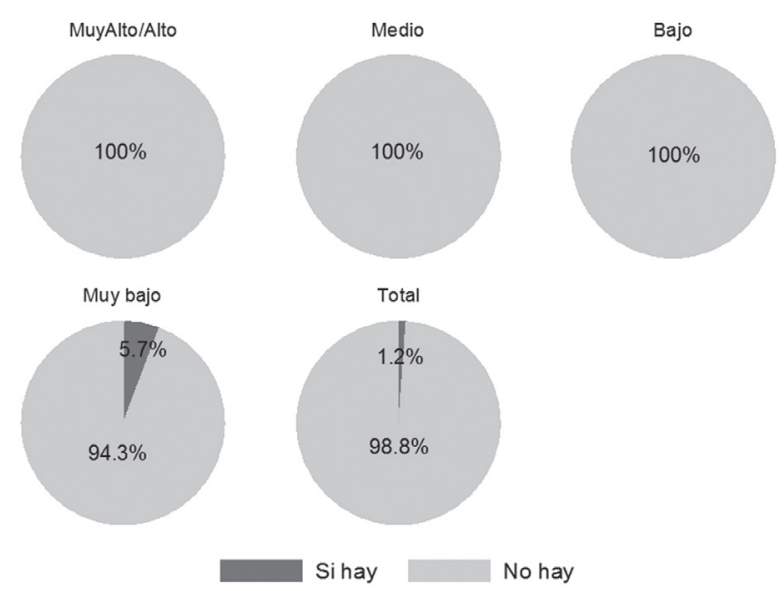

Figura 3. Ciclovías por índice de marginación

La casi ausencia total de ciclovías representa una barrera muy importante para la actividad física y el transporte activo en Cuernavaca, ya que está reconocida como un motivador y un desencadenante de hábitos favorables para la actividad física. 


\section{Espacios deportivos}
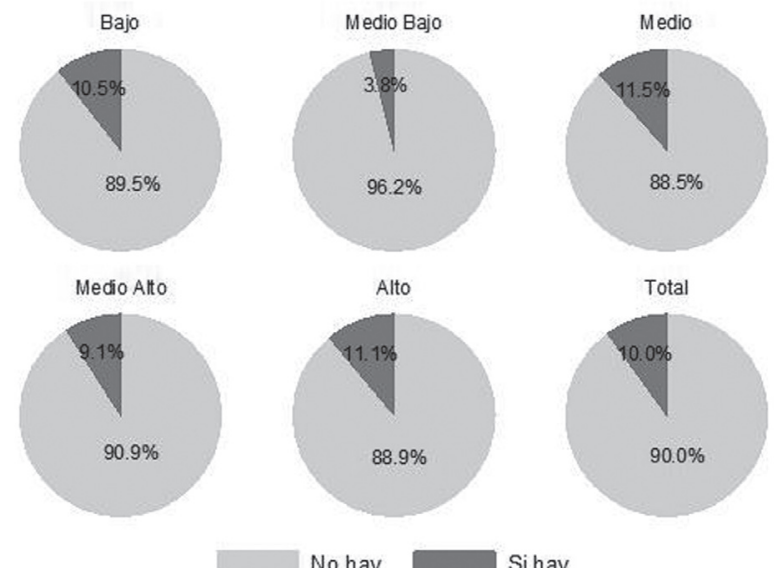

Sihay

Figura 4. Espacios deportivos por nivel socieconómico

La Figura 4, muestra como solo un $10 \%$ de los 20 AGEBS estudiados tiene espacios deportivos; lo cual representa una barrera importante de accesibilidad a áreas que promuevan la actividad física.

La disponibilidad de espacios deportivos es más alta en el nivel socioeconómico medio con $11.49 \%$ y más baja en el Nivel socioeconómico medio -bajo, con un 3.8\% (Figura 4). También se resalta que el uso inadecuado muchos de estos espacios.

\section{Tránsito}

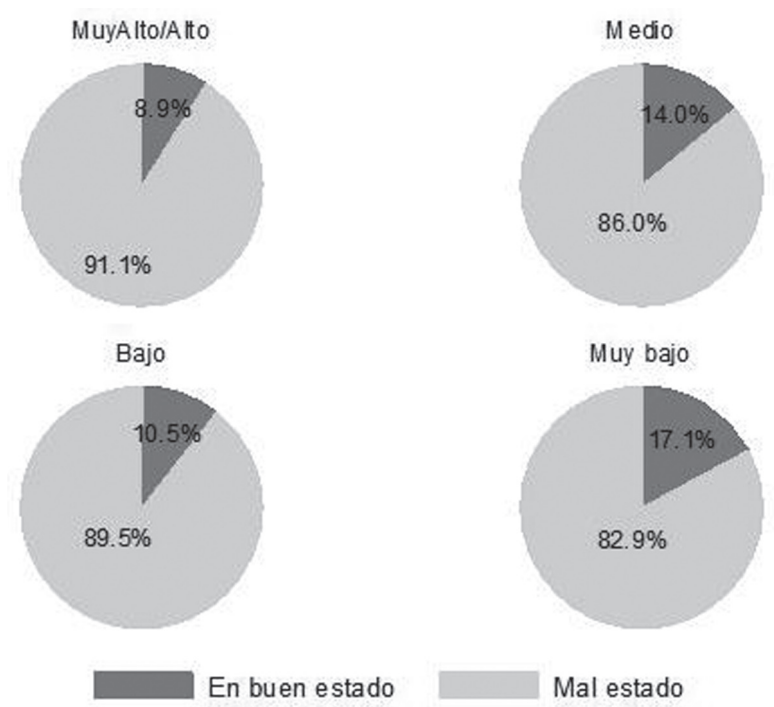

Figura 5. Estado de las vías de transporte por nivel de marginación
Hace referencia este apartado al total de AGEBS estudiados y a todos los niveles de marginación. La Figura 5, muestra cómo el $82.86 \%$ de las vías está en mal estado, entendiéndose esto como mal uso de las vías, carencia de señalización que representa riesgos para caminar; factores que representan importantes barreras para la actividad física y el transporte activo (Figura 3).

\section{Análisis Socioeconómico}

Las barreras para la actividad física están distribuidas socioeconómicamente; en los tres niveles de marginación (alto, medio y bajo) se encontraron barreras siendo en el nivel alto donde se encontró la mayoría.

\section{Nivel de marginación alto}

Para los AGEBS de nivel de marginación alto se encontró que el tipo de comunidad va de lo urbano a lo rural; predomina la poca accesibilidad a espacio deportivos adecuados, a calles y banquetas seguras y señalizadas, poca infraestructura peatonal; los cuales representan barreras importantes para la actividad física (Cuadro 3).

\section{Nivel de marginación medio}

Para este grupo de AGEBS se encontró ausencia de ciclovías, banquetas en su mayoría obstruidas, presencia vías de transporte para caminar pero no señalizadas en tramos empedradas; poca señalización para circular peatones, calles estrechas, dominancia de grafitis, un solo puente peatonal; los cuales representan barreras para el transporte activo de las personas. En el cuadro 3 se presenta la condensación del análisis de las imágenes fijas, por índice de marginación, resultados que enriquecen y amplían los datos obtenidos de las guías de observación.

\section{Nivel de marginación bajo}

Referente a los AGEBS de nivel de marginación bajo, se reportó como atributos sociales un nivel socioeconómico alto, predominio de comunidad urbana. Predomina la poca existencia espacio deportivos públicos y más de los privados, presencia de calles y banquetas inseguras y poco señalizadas, buen acceso a instalaciones culturales y educativas. De esta forma espacios deficientes para el transporte activo son una constante y representan barreras para la actividad física al igual que en los demás índices de marginación. 
Análisis de algunas barreras del ambiente construido para la actividad física en la Ciudad de Cuernavaca, Morelos, México

Tabla 3. Descriptores de imágenes por nivel de marginación en banquetas, tránsito y espacios deportivos

\begin{tabular}{|c|c|c|c|}
\hline $\begin{array}{c}\text { ÍNDICE DE } \\
\text { MARGINACIÓN }\end{array}$ & BANQUETAS & TRÁNSITO & ESPACIOS DEPORTIVOS \\
\hline Alto & $\begin{array}{l}\text { Carencia de banquetas o si existen } \\
\text { están obstruidas. Banquetas angostas } \\
\text { u obstruidas y nulas. Banquetas } \\
\text { estrechas, obstruidas o inexistentes }\end{array}$ & $\begin{array}{l}\text { Predominante de tierra, empedrado, } \\
\text { sin señalización, estrechas, carencia } \\
\text { de señalización. }\end{array}$ & $\begin{array}{l}\text { No hay ciclovías. Hay una } \\
\text { unidad deportiva pública, } \\
\text { espacios destinados a deportes } \\
\text { privados y un campo deportivo } \\
\text { público. }\end{array}$ \\
\hline Medio & $\begin{array}{l}\text { Alternan calles con y sin banquetas. } \\
\text { Cuando existen, se encuentran } \\
\text { obstaculizadas, angostas y en su } \\
\text { mayoría obstruidas, deterioradas y } \\
\text { estrechas. }\end{array}$ & $\begin{array}{l}\text { Sí hay vías de transporte, pero no } \\
\text { señalizadas en tramos empedradas. } \\
\text { Sin señalización para circular } \\
\text { peatones, calles estrecha. }\end{array}$ & $\begin{array}{l}\text { No hay ciclovías. Hay un solo } \\
\text { espacio deportivo público. }\end{array}$ \\
\hline Muy bajo & $\begin{array}{l}\text { Banquetas que en algunos tramos } \\
\text { presenta obstrucciones, obstruidas } \\
\text { por automóviles. En algunos tramos } \\
\text { carencia de banquetas u obstruidas } \\
\text { por raíces y jardineras o comercio } \\
\text { ambulante. Banquetas de ancho } \\
\text { adecuadas, pero obstruidas por } \\
\text { automóviles o raíces de los árboles. }\end{array}$ & $\begin{array}{l}\text { Vías de transporte, no señalizadas, } \\
\text { angostas, por tramos empedradas, } \\
\text { predomina la falta de señalización. } \\
\text { Vías de transporte, que en algunos } \\
\text { tramos aparece deteriorada. No } \\
\text { tiene señalización para el cruce de } \\
\text { peatones. }\end{array}$ & $\begin{array}{l}\text { Se observa una ciclovía en } \\
\text { buenas condiciones, centros } \\
\text { deportivos privados, un centro } \\
\text { comunitario y una cancha } \\
\text { básquet pública }\end{array}$ \\
\hline
\end{tabular}

\section{DISCUSIÓN}

"La verdadera riqueza es la salud, el cuerpo se nutre del ejercicio como una flor se nutre del Sol" ${ }^{14}$.

Los resultados obtenidos en este estudio implican que existen barreras muy importantes para que la población de Cuernavaca realice actividad física, se movilice activamente y con seguridad. Existen políticas y programas que promueven la actividad física pero no se ejecutan. Sobre esto se hace mención que dentro de las recomendaciones mundiales para la promoción de la actividad física destacan el análisis de la planificación urbana y transporte, revisar las políticas públicas medioambientales y las condiciones e instalaciones seguras para la práctica de la misma². Por ende, Cuernavaca presenta un atraso en desarrollo considerable ante estas recomendaciones mundiales.

El peso de los las variables del ambiente construido y socioeconómicas son muy importantes, en este estudio se evidencia como en aspectos como las ciclovías, transporte y diseño adecuado de banquetas para caminar y buena calidad de espacios deportivos para el deporte y la recreación existe poco desarrollo. Los AGEBS con mayor grado de marginación, presentan menor desarrollo evidenciando una tendencia de inequidad social, descuido de las políticas públicas que cobijen a la población con menor ingreso. Para nosotros las barreras para la actividad física pueden ser sinónimo de inactividad física. La prevalencia de mortalidad atribuible a la inactividad física para México es del $10.1 \%$ para el total de muertes en la República, porcentaje elevado que implica costos muy altos para el sistema de salud y un grave impacto social y laboral; sin embargo, esta prevalencia no es la más alta de la región, pues países como Argentina con un 18.2\% y República Dominicana con un $16.0 \%$, Brasil con $13.2 \%$ presentan los más altos índices ${ }^{15}$. Cifras similares a las de México presentan países como Uruguay, Dominica, Colombia y ecuador ${ }^{15}$. Es importante resaltar cómo un país como Guatemala con uno de los mayores índices de marginación y desnutrición de mundo presenta la prevalencia más baja de muertes atribuibles a la inactividad física con un $4.3 \%$, y cómo un país europeo como Malta posee la prevalencia más alta del mundo con un $19.2 \%{ }^{15}$.

En concordancia con un estudio importante ${ }^{16}$, los esfuerzos por aumentar la orientación peatonal del entorno construido a través de un amplio desarrollo, la conectividad de la calle y un buen diseño, entre otras medidas, pueden mejorar tanto la viabilidad y el atractivo de caminar y montar en bicicleta por reducción de las barreras físicas y de hecho se afirma que aumentar la caminata diaria podría mejorar la salud y calidad de vida de las personas ${ }^{17}$.

En este estudio se encontró, que en el caso concreto de Cuernavaca el índice de marginación está relacionado con mayores o menores oportunidades para realizar actividad física. En otro estudio ${ }^{18}$ se reveló tres temas que reflejan factores que limitan la actividad física: (a) falta de apoyo para la actividad física, (b) las rutinas institucionales generalizados, y (c) las limitaciones del entorno físico. En dicho estudio los participantes consideraron importante la actividad física para la preservación de la salud, los factores individuales, 
estructurales y ambientales; resultados que confirman la necesidad de desarrollar estrategias prácticas y formas de abordar las barreras modificables ${ }^{18}$.

Es importante resaltar que los índices de transitabilidad se correlacionan con los índices de masa corporal (IMC) y la actividad física de las poblaciones ${ }^{19,20}$. Debido a las diferencias que existen entre la salud de personas con diferentes patrones de transitabilidad, ha sido sugerido que se necesita más investigación para encontrar otros factores del entorno construido para ser incluidas en los índices de transitabilidad ${ }^{21}$.

Caminar en Cuernavaca es un reto, debido a la poca planificación de sus espacios peatonales, a su inclinación geográfica, aspecto que priva a la población de uno de los beneficios más importantes de la transitabilidad, que es la disminución del uso del automóvil en la comunidad. Tener opciones para caminar contribuye al cuidado del medio ambiente estimulando la actividad física ya que las emisiones de carbono pueden reducirse si se usa menos el automovil ${ }^{22}$.

Respecto a caminar también se ha encontrado que podría tener beneficios económicos, como la accesibilidad, ahorro de costos tanto a particulares como a la eficiencia pública, el aumento del uso del suelo, el aumento de habitabilidad, los beneficios económicos de una mejor salud pública y el desarrollo económico, entre algunos otros $^{22}$. Es de resaltar como el World Cancer Research Fund y el American Institute for Cancer Research, publicaron un informe sugiriendo que las nuevas recomendaciones de diseño vial deben ser diseñadas para estimular el andar pie, con el argumento de que caminar contribuye a la reducción del cáncer ${ }^{23}$. Para Lobelo, estrategias para la disminución de la inactividad física pueden conllevar a reducciones progresivas de la carga de mortalidad ${ }^{24}$.

Sin duda, el aporte metodológico de este estudio es un elemento fundamental, propuesta innovadora que favorece el aprovechamiento de la riqueza de las imágenes fijas y todo su contenido abierto a múltiples áreas de investigación y que es factible de replicarse en nuestra opinión en casi cualquier lugar del mundo. Muestra de ello, es el uso de las imágenes fijas en estudios propios como en la epidemiologia social, en donde una observación sistemática de las comunidades a través de las imágenes favorece un mayor entendimiento de la relación entre la salud y enfermedad, estimulando la creación de un puente entre los investigadores y la población ${ }^{25}$. Este presente estudio se diferencia metológicamente de otros que utilizan las imágenes fijas, en algunos aspectos ${ }^{25}$ : no utiliza la técnica llamada "Photovoice" (técnica bastante difundida en los estudios con imágenes), hace énfasis en todos los niveles marginación existentes para una población urbana en México y está dirigido a documentar específicamente posibles barreras para la actividad física y no elementos del ambiente que pudieran estar en relación con otros daños a la salud. También se diferencia en que en México no existe la amplia facilidad social para tomar públicamente fotografías a elementos del ambiente construido como casas, como sucede en países como Estados Unidos $^{25}$. Este estudio también presentó algunas posibles limitaciones metodológicas, al ser el primer estudio de su tipo en México, propias del trabajo de campo y de un estudio sobre datos secundarios; tales como las categorías de análisis de las imágenes y guías de observación, que fueron elegidas a conveniencia para los objetivos de este estudio y no bajo un marco de referencia de otros estudios, al no haber estudios de este tipo en Latinoamérica. También la asignación de valores a las observaciones encontradas en las guías de observación tuvo como finalidad presentar la proporción de estas mismas y de esta forma caracterizar mejor la problemática estudiada. Sin duda otra limitación fue la creciente violencia y desconfianza social imperante en México en los últimos años que fueron elementos presentes en el trabajo de campo (recolección de datos) pero que no impidieron cumplir con los objetivos de campo propuestos. En la actualidad hay esfuerzos metodológicos para entender mejor el ambiente construido en algunos países del mundo, ya que este es un campo de creciente interés para la salud pública y el bienestar social.

Estudios como este, procuran servir de soporte científico basado en técnicas más novedosas de análisis en investigación en salud, para que dentro de las propuestas de salud pública que se promueven en la ciudad de Cuernavaca, se considere el ambiente construido con una relación estrecha con la percepción de seguridad y su transformación como un ente generador de espacios favorables para la actividad física y disminución de la violencia ${ }^{26}$ y que sea replicable en México y en cualquier población con características similares que Cuernavaca. Sobre entornos similares en Latinoamérica, podemos mencionar un estudio en la ciudad Cali, Colombia ${ }^{27}$, urbe que comparte elementos similares con Cuernavaca como importantes índices de delincuencia y retrasos en la organización vial, aunque con población un poco mayor; estudio que utilizó dentro de su metodología las imágenes para documentar fallas en la infraestructura urbana y su posible relación con los accidentes viales ${ }^{27}$, tema de salud de alta gravedad y que amplía el valor 
Análisis de algunas barreras del ambiente construido para la actividad física en la Ciudad de Cuernavaca, Morelos, México

científico de las imágenes fijas en múltiples temas en relación a la salud; sin embargo tanto los objetivos de ese estudio como la forma de tomar y analizar (categorías) las fotografías son diferentes a las de este presente estudio.

Consideramos y fue el propósito de este estudio que la identificación y abolición de las barreras deben estar dentro las prioridades de las políticas de salud públicas y que las intervenciones deben procurar dicha transformación, de esta forma se superará la tendencia de solamente informar sobre los beneficios de la actividad física que predominan en la gran mayoría de las recomendaciones e intervenciones.

\section{LIMITACIONES}

Este estudio presentó algunas limitaciones propias del trabajo de campo en una ciudad con altos índices de inseguridad como lo es Cuernavaca, es decir; tomar fotos en una calle no siempre es bien visto para los habitantes de la misma. Para lo cual, hubo comunicación e información constante con las personas de la comunidad interesadas en las acciones del trabajo de campo. Así como también hubo limitaciones en la implementación del análisis de imágenes fijas al no encontrar estudios de salud previos similares en Latinoamérica, siendo esta la primera vez que un estudio de salud en México utiliza y desarrolla esta técnica. Pero consideramos que estas limitaciones no afectaron de forma alguna los resultados obtenidos.

\section{CONSIDERACIONES ÉTICAS}

Este estudio fue aprobado por el comité de ética en investigación del Instituto Nacional de Salud Pública de México.

\section{CONFLICTOS DE INTERES}

Los autores declaran no tener conflictos de intereses.

\section{REFERENCIAS}

1. Cortés D; El poema total; Aguas calientes; Azzabug; 200; 6-135.

2. World Health Organization. Recomendaciones mundiales sobre actividad física para la salud. Geneva: WHO Library Cataloguing-in-Publication Data. 2010.

3. Pi-Sunyer FX. Obesity: criteria and classification. Proc Nutr Soc. 2000; 59(4): 505-509.

4. Olaiz-Fernandez G, Rivera-Dommarco J, Shamah-
Levy T, Rojas R, Villalpando-Hernández S, Hernandez-Avila M, et al. Encuesta Nacional de Salud y Nutrición 2006. Cuernavaca, México: Instituto Nacional de Salud Pública, 2006.

5. United States. Public Health Service. Office of the Surgeon General, Centers for Disease Control, National Center for Chronic Disease Prevention, Health Promotion (US), President's Council on Physical Fitness, Sports (US). Physical activity and health: a report of the Surgeon General. Government Printing Office; 1996.

6. Cerón Souza C. Editorial Los determinantes sociales de la salud. Rev Univ Salud. 2012; 14(1): 5

7. Cervero R, Sarmiento OL, Jacoby E, Gomez LF, Neiman A. Influences of built environments on walking and cycling: lessons from Bogotá. Int $\mathrm{J}$ Sust Transportation. 2009; 3(4):203-226. DOI: $10.1080 / 15568310802178314$.

8. Center for Understanding the Built Environment (CUBE). Teach children about the built environment by building a city out of recycled materials. 2013 .

9. Fox KR. The influence of physical activity on mental well-being. Public Health Nutr. 1999; 2(3a): 411-418. DOI: $10.1017 /$ S1368980099000567.

10. 4th international congress on Physical Activity and Public Health 2012.

11. Hernández J, Vieyra A. Riesgo por inundaciones en asentamientos precarios del periurbano. Morelia, una ciudad media mexicana: ¿El desastre nace o se hace?. Rev Geogr Norte Gd. 2010; 47: 45-62. DOI: /10.4067/S0718-34022010000300003.

12. Gastaminza, F. El análisis documental de la fotografía. 2001.

13. Hernández A, Gómez LF, Parra DC. Ambientes urbanos y actividad física en adultos mayores: relevancia del tema para América Latina. Rev Salud pública. 2010; 12(2): 327-335. DOI: 10.1590/ S0124-00642010000200016.

14. Cortés D. Lo que el maestro callaba; Aguas calientes. Azzabug. 2008; 2-77.

15. Das P, Horton R. Rethinking our approach to physical activity. Lancet. 2012; 380(9838): 189190. DOI: 10.1016/S0140-6736(12)61024-1.

16. Neumann E, Xaviera V. Transporte urbano no motorizado: el potencial de la bicicleta en la ciudad de Temuco. Rev INVI. 2011; 26(72): 153-184. DOI: 10.4067/S0718-83582011000200006.

17. Handy SL, Boarnet MG, Ewing R, Killingsworth RE. How the built environment affects physical activity: views from urban planning. Am J Prev Med. 2002; 23(2 Suppl): 64-73.

18. Benjamin K, Edwards N, Guitard P, Murray MA, Caswell W, Perrier MJ. Factors that influence 
physical activity in long-term care: perspectives of residents, staff, and significant others. Can J Aging. 2011; 30(2): 247-258. DOI: 10.1017/ S0714980811000080.

19. Frank LD, Sallis JF, Conway TL, Chapman JE, Saelens BE, Bachman W. Many pathways from land use to health. J Am Planning Association. 2006; 72(1): 75-87. DOI: 10.1080/01944360608976725.

20. Frank LD, Schmid TL, Sallis JF, Chapman J, Saelens BE. Linking objectively measured physical activity with objectively measured urban form: Findings from SMARTRAQ. Am J Prev Med. 2005; 28(2): 117-125.

21. Lopez RP, Hynes PH. Obesity, physical activity, and the urban environment: public health research needs. Environ Health. 2006; 5: 25. DOI: 10.1186/1476069X-5-25.

22. Littman T. Economic value of walkability. J Transport Res Board. 2003; 10(1): 3-11.

23. Hitti M. Report: Good diet, physical activity and healthy weight may prevent $34 \%$ of 12 common cancers in the U.S. WebMD Health News. 2009.

24. Lobelo F, Pate R, Parra D, Duperly J, Pratt M. Carga de mortalidad asociada a la inactividad física en Bogotá. Rev Salud Pública. 2006; 8(Sup 2): 28-41.

25. Cannuscio CC, Weiss EE, Fruchtman H, Schroeder J, Weiner J, Asch DA. Visual epidemiology: photographs as tools for probing street-level etiologies. Soc Sci Med. 2009; 69(4): 553-564. DOI: $10.1016 /$ j.socscimed.2009.06.013.

26. Guerrero R, Concha-Eastman A. An epidemiological approach to the prevention of urban violence: The case of Cali, Colombia. World Health Popul. 2012; 1-11. DOI: 10.12927/whp.17590.

27. Echeverry A, Mera JJ, Villota J, Zárate LC. Actitudes y comportamientos de los peatones en los sitios de alta accidentalidad en Cali. Colomb Med. 2005; 36(2): 79-84 